03,09

\title{
Зависимость свойств вариативных градиентно-пористых структур кремния от метода формирования
}

\author{
(С) К.И. Рубцова, М.Д. Силина \\ Национальный исследовательский технологический университет „МИСиС“, \\ Москва, Россия \\ E-mail: rubcova.karina@gmail.com, theinnercrow@yandex.ru
}

Поступила в Редакцию 16 июля 2019 г.

В окончательной редакции 16 июля 2019 г.

Принята к публикации 25 июля 2019 г.

Получена серия образцов градиентно-пористых структур кремния с кристаллографическими ориентациями (100) и (111) методом глубокого анодного травления. Показаны зависимости скорости глубокого анодного травления и глубины пористого слоя образцов от плотности анодного тока. Исследованы коэффициенты поглощения и отражения образцов методом оптической спектрометрии в зависимости от их кристаллографической ориентации и глубины пористого слоя. Определено влияние водных растворов на оптические свойства образцов.

Ключевые слова: пористый кремний, ГПК-Var, анодное травление, коэффициент отражения.

DOI: $10.21883 /$ FTT.2019.12.48540.23ks

\section{1. Введение}

Пористый кремний (ПК) является одним из самых известных среди наноматериалов, открытый А. Улиром (Uhlir) [1] в середине прошлого столетия. ПК является перспективным материалом, свойства которого активно исследуются в 40 странах мира, а объем научных публикаций составляет не менее 500 научных работ в год [2], что говорит об высокой актуальности исследования данного материала.

ПК широко используется в микро- и оптоэлектронике ввиду унаследованного порядка расположения атомов от монокристаллической подложки. Кроме того, возможность формирования вариативной градиентно-пористой структуры кремния (ГПК-вар) в едином процессе глубокого анодного травления позволяет использовать внешний наноструктурированный слой (благодаря „подложке“ из макропористого кремния). Его характеризует высокое удельное сопротивление, низкая величина модуля Юнга, высокая удельная площадь поверхности и размер пор от долей до десятков нанометров [3]. Сочетание этих физико-химических свойств определяет пористый кремний как уникальный многофункциональный материал.

\section{2. Эксперимент}

\section{1. Получение образцов методом глубокого анодного травления}

Для создания серии образцов ПК выбран метод глубокого анодного травления монокристаллического кремния в растворе плавиковой кислоты и изопропилового спирта в соотношении 6:1. Такой выбор обусловлен рядом преимуществ данного метода, таких как его доступность и возможность локального формирования на пластине требуемых пористых областей; раствор электролита выбран на основе ранее полученных данных [4].

В работе использовались монокристаллические пластины кремния марок КДБ-10 с кристаллографической ориентацией поверхности пластин (100) и (111), а также кислота фтороводородная (49\%) ОСЧ „27-5“ НF, ТУ 6-09-34-01-88 и изопропиловый спирт ОСЧ 11-5 ТУ 2632-064-44493179-01. Для увеличения смачиваемости поверхности и получения однородного фронта травления в раствор электролита добавляется катионное поверхностно-активное вещество раствор $\left(10^{-3} \mathrm{~mol} / \mathrm{l}\right)$ хлорид цетилтриметиламмония $\left(\mathrm{CH}_{3}\left(\mathrm{CH}_{2}\right){ }_{15} \mathrm{~N}\left(\mathrm{CH}_{3}\right)_{3} \mathrm{Cl}\right)-\mathrm{CTAC}$.

Подготовлены 2 серии образцов на основе КДБ-10 (100) в количестве 3 штук и (111) в количестве 3 штук. Образцы подвергались глубокому анодному травлению в течение определенного промежутка времени на основе данных о скоростях травления кремния до получения пористого слоя толщиной $40 \mu \mathrm{m}$ при плотностях тока анодного травления 10,15 и $20 \mathrm{~mA} / \mathrm{cm}^{2}$.

\section{2. Оборудование}

Образцы исследованы в аккредитованной испытательной лаборатории „Монокристаллы и заготовки на их основе“ НИТУ „МИСиС“ спектрофотометрическим методом отражения света на спектрофотометре „Саry 5000“ (компания „Agilent Technologies“) с автоматической универсальной измерительной приставкой (UMA) при углах падения света на поверхность образца $10^{\circ}-20^{\circ}$ и $20^{\circ}-40^{\circ}$ в диапазоне длин волн $(0-2500) \mathrm{nm}$.

Также образцы изучены с помощью сканирующего электронного микроскопа JEOL JSM-6700F (Field Emission Scanning Electron Microscope). 

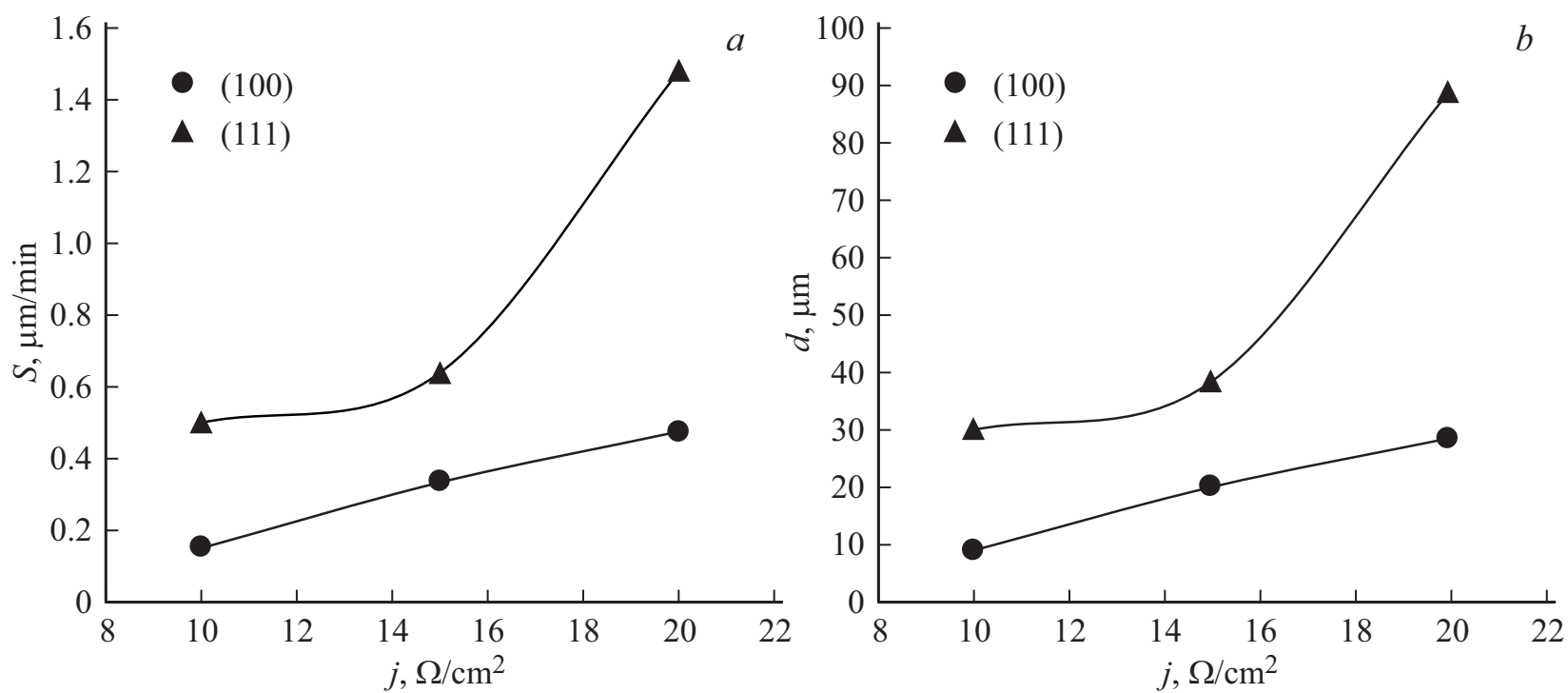

Рис. 1. a) Зависимость скорости глубокого анодного травления для образцов кремния (100) и (111) от плотности анодного тока. b) Зависимость глубины пористого слоя для образцов кремния (100) и (111) от плотности анодного тока.

Для оценки взаимодействия полученных образцов с водой проводилось измерение показателей $\mathrm{pH}$. Измерения происходили с помощью стеклянного и хлорсеребряного электродов, предварительно откалиброванных в буферных растворах. Для работы использовался pH-метр лабораторный типа „РН-673 М“ с диапазоном измерения от -1 до $+14 \mathrm{PH}$.

\section{3. Результаты и обсуждение эксперимента}

В работе исследованы режимы формирования ГПК-Var структур анодным травлением пластин монокристаллического кремния $p$-типа проводимости в безводном растворе плавиковой кислоты (HF) в изопропиловом и этиловом спирте. На рис. $1, a, b$ представлены экспериментальные зависимости скоростей глубокого анодного травления и глубины пористого слоя от плотности анодного тока для образцов кремния марки КДБ-10 (111) в сравнении с КДБ-10 (100), что подтверждено в литературных данных [4].

При этом более воспроизводимые ГПК-Var структуры формируются в растворах на основе изопропилового спирта, что можно объяснить низким содержанием воды в данном растворе (концентрация спирта 98\%) по сравнению с этиловым (концентрация спирта не выше 96\%). Также выявлено, что образцы с кристаллографической ориентацией пластины (111) имеют бо́льшую глубину травления, чем образцы (100) при равных условиях травления.

Подготовленная серия образцов на основе монокристаллического кремния исследована на зависимость коэффициентов поглощения и отражения методом оптической спектрометрии. Полученные спектры представлены на рис. 2, 3 .

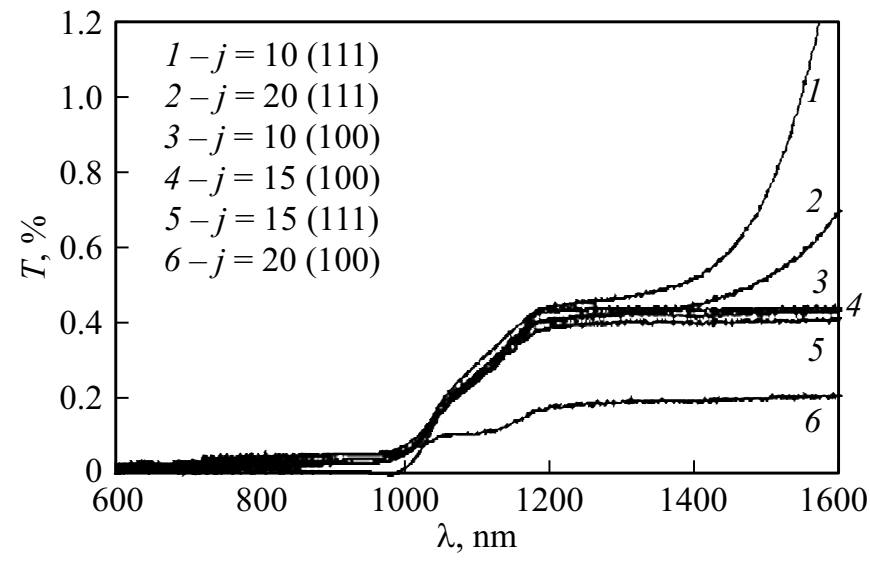

Рис. 2. Зависимость коэффициента поглощения пористого слоя от длины волны.

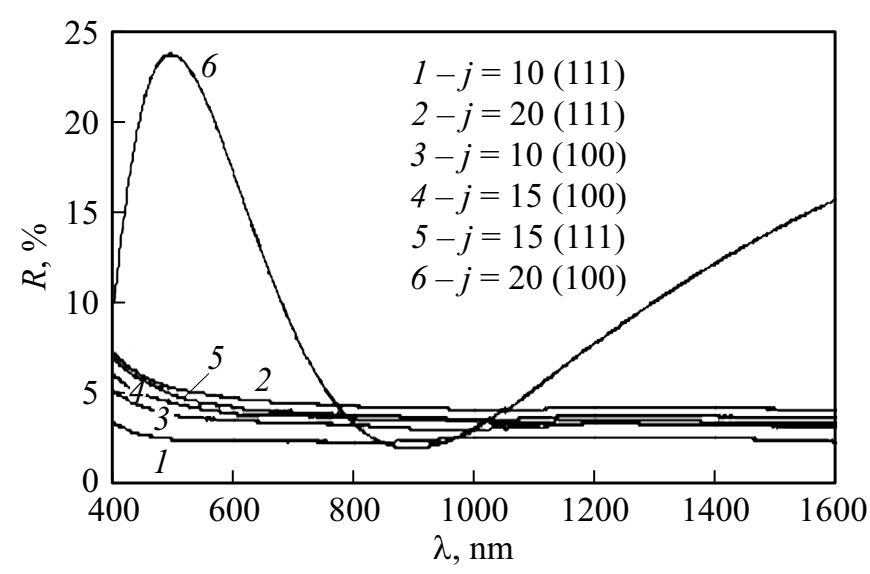

Рис. 3. Зависимость коэффициента отражения пористого слоя от длины волны. 


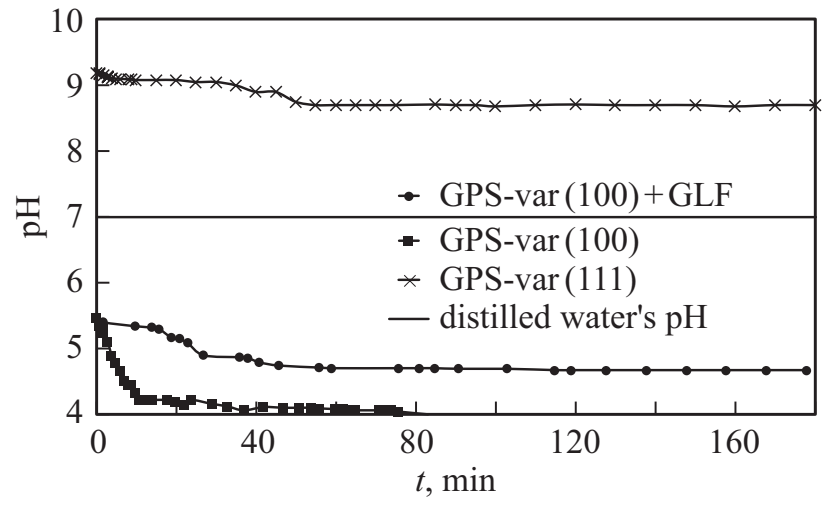

Рис. 4. Зависимости изменения $\mathrm{pH}$ растворов от времени выдержки образцов пористого кремния в водных растворах.

Наилучшую зависимость коэффициента отражения (не превышает 3\%) продемонстрировал образец с кристаллографической ориентацией пластины (100), полученный в ходе глубокого анодного травления при плотности тока $10 \mathrm{~mA} / \mathrm{cm}^{2}$. При этом коэффициент поглощения не превышает $0,5 \%$ на участке длин волн более $1100 \mathrm{~nm}$ и не более $0,1 \%$ до $1000 \mathrm{~nm}$.

Также произведена качественная оценка устойчивости образцов с водными растворами. Для повышения устойчивости внешнего наноструктурированного слоя ГПК-Var структуры к воздействию водных растворов предложено пассивировать нанопористый слой графеноподобными пленками (ГПП), ввиду того что в работе [5] показан механизм взаимодействия пористого кремния с водой. Для сравнения образцы ГПК-Var структур и
ГПК-Var структур с пассивацией выдерживались в воде в течение $180 \mathrm{~min}$. Результат представлен на рис. 4.

В отличие от данных статьи [4], на предмет взаимодействия с водными растворами был исследован образец кристаллографической ориентации (111), который показал более высокую устойчивость к воздействию водного раствора даже с повышенным значением $\mathrm{pH}$, о чем свидетельствует быстрый выход значения $\mathrm{pH}$ на насыщение. Образцы с ориентацией (100) показали меньшую устойчивость. Поверхность ГПК-Var (100) была разрушена за $80 \mathrm{~min}$, а ГПК-Var $(100)+$ ГПП выдержал воздействие раствора, однако по сравнению с ГПК-Var (111) вышел медленнее на насыщение. Значение $\mathrm{pH}$ дистиллированной воды дано для сравнения.

Образцы ГПК-Var (100) и ГПК-Var $(100)+$ ГПП после выдержки в водном растворе изучены на предмет коэффициента отражения в диапазоне длин волн от 200 до $2400 \mathrm{~nm}$ (рис. 5).

Как следует из приведенных экспериментальных данных, зависимость коэффициента отражения $R$ от длины волны носит нелинейный характер и наименьшие значения $R$ соответствуют более высоким значениям длин волн. При этом угловая зависимость коэффициента отражения также более характерна для больших длин волн.

Коэффициент отражения ГПК-Var слоев после выдержки образцов в водном растворе значительно уменьшился. В то же время пленка ГПК-Var в результате воздействия воды подверглась сильному разрушению, приобрела выраженный оранжевый цвет, характерный для наноструктурированных и люминесцирующих даже при освещении дневным светом пористых структур.
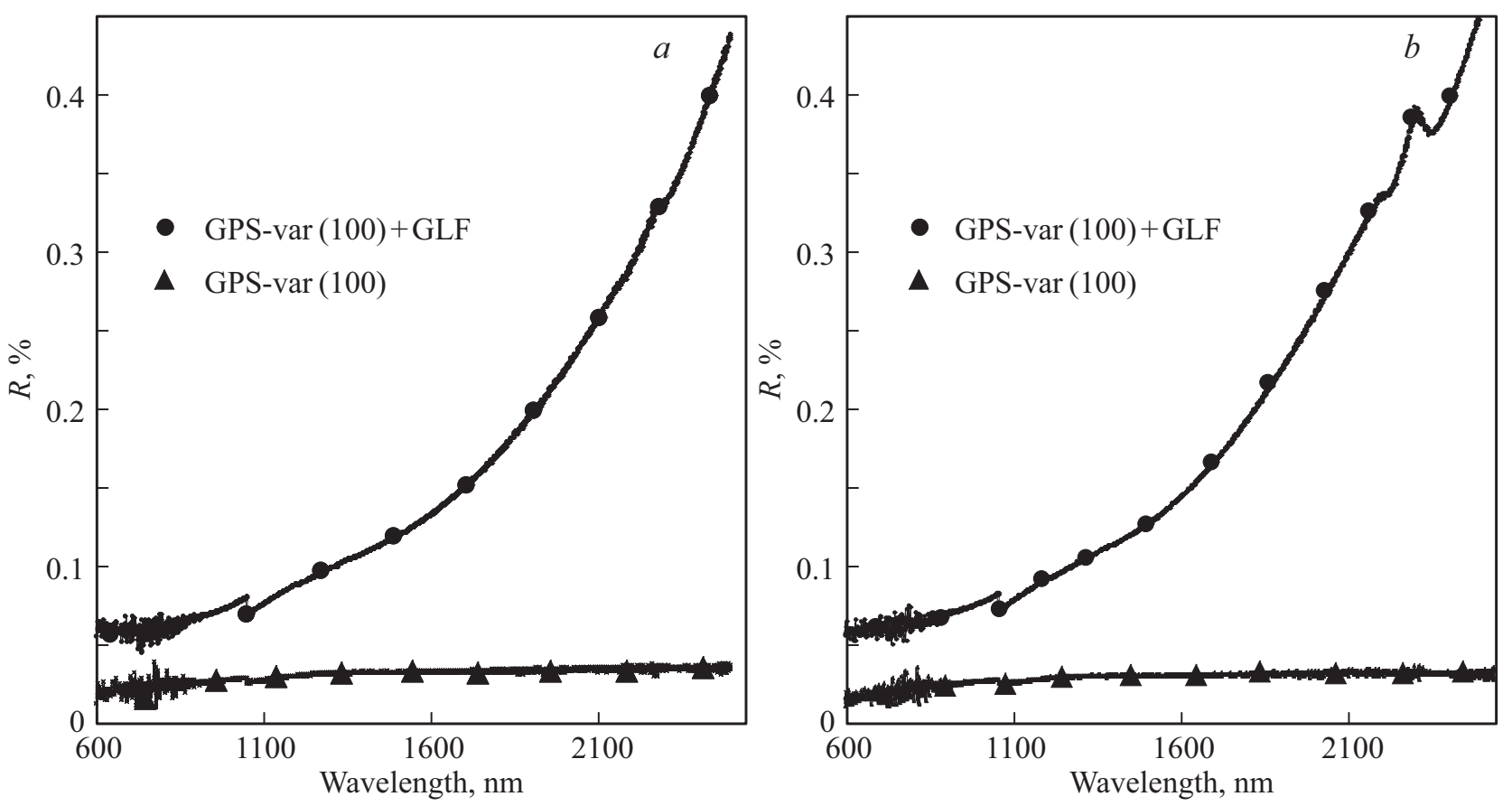

Рис. 5. Коэффициенты отражения образцов после выдержки в водных растворах при углах падения и отражения $a) 10^{\circ}-20^{\circ}$, b) $20^{\circ}-40^{\circ}$. 
Коэффициент $R$ наноструктурированного слоя имеет минимальное значение и не зависит от длины волны света.

\section{4. Заключение}

В данной работе исследованы режимы формирования ГПК-Var структур. Установлен оптимальный режим формирования пористых слоев методом глубокого анодного травления монокристаллических пластин кремния в растворе электролита (плавиковая кислота и изопропиловый спирт в соотношении 6:1). Проведено сравнение свойств структур с кристаллографическими ориентациями (100) и (111). Серии образцов исследованы методом оптической спектрофотометрии, установлены зависимости коэффициентов отражения и поглощения для пористых слоев на основе монокристаллических пластин кремния марки КДБ-10.

Показано изменение свойств ГПК-Var структур после взаимодействия с водными растворами. Полученные экспериментальные данные дают основание предположить, что использование наноструктурированных структур на основе ГПК-Var слоев позволяет создавать покрытия с коэффициентом поглощения не менее 99\% в рассмотренном диапазоне длин волн.

\section{Благодарности}

Авторы статьи выражают глубокую благодарность своему научному руководителю Е.А. Гостевой, а также научному консультанту В.В. Старкову за неоценимую помощь в проводимом исследовании.

\section{Конфликт интересов}

Авторы заявляют, что конфликт интересов отсутствует.

\section{Список литературы}

[1] A. Uhlir. Bell System Tech. J. 35, 333 (1956).

[2] С.П. Зимин. Сорос. образоват. журн. 8101 (2004).

[3] В.В. Старков. Все материалы 4, 13 (2009).

[4] V.V. Starkov, D.M. Sedlovets, E.A. Gosteva. Appl. Phys. A. 125, 376 (2019).

[5] Е.А. Тутов. Сорбционные и хроматографические процессы 9, 131 (2009).

Редактор Д.В. Жуманов 